This is a postprint version of the following published document:

Pernas-Sánchez, J.; Artero-Guerrero, J. A.; Varas, D.; López-Puente, J. (2015).

"Analysis of Ice Impact Process at High Velocity". Experimental Mechanics, v. 55, Issue 9, July, pp. 1669-1679.

DOI: $10.1007 / \mathrm{s} 11340-015-0067-4$

Proyecto DPI2013-41094-R

(C) Society for Experimental Mechanics 2015 


\title{
Analysis of Ice Impact Process at High Velocity
}

\author{
J. Pernas-Sánchez $^{1}$ • J.A. Artero-Guerrero ${ }^{1}$ - D. $\operatorname{Varas}^{1}$ • J. López-Puente ${ }^{1}$
}

\begin{abstract}
In this work the high velocity impact of ice spheres is analysed. An experimental methodology has been developed in order to launch, at high velocity, ice spheres of different diameters against a load cell to measure the force induced during the impact. An analysis of the influ-ence of the ice mass on the impact force is accomplished using the contact force which was calculated by means of an inverse problem technique. Finally a study of the impact phenomenon has been performed using the videos obtained with a high speed camera.
\end{abstract}

Keywords: Ice behaviour; High velocity impact; High strain rate; Experimental; Contact force

\section{Introduction}

During its service life, aircraft structures could be subjected to different kind of loads. Focusing on impact loads, it is

This research was done with the financial support of the Spanish Ministry of Education under Project reference DPI2013-41094-R.

J. López-Puente jlpuente@ing.uc3m.es

J. Pernas-Sánchez jpernas@ing.uc3m.es

J.A. Artero-Guerrero jartero@ing.uc3m.es

D. Varas

dvaras@ing.uc3m.es

1 Department of Continuum Mechanics and Structural Analysis, University Carlos III of Madrid, Avda. de la Universidad, 30, 28911 Leganés, Madrid, Spain easy to find situations in which a part of a structure can be subjected to an impact of a foreign object. Some examples could happen during take off and landing (due to runaway debris), in case of uncontained engine rotor failure, bird strike and, in particular, impact of ice [1]. The ice from hail could impact the aircraft when passing through a storm, but also the ice that is produced in convex parts such as leading edges could be released and impact to the aircraft structures. Therefore it is important to understand how the ice interacts with the structure when impacting at high velocities, and in particular which is the contact force that the ice induces during the impact.

Several works [2-5] have studied the mechanical behaviour of the ice, showing its dependence on temperature, micro-structure and strain rate. Regarding this last dependence, the ice exhibits a ductile to fragile transition at approximately $10^{-3} s^{-1}$ [6]; this ductility is due to a refreeze process which could not occur at high strain rates. Polycrystalline ice Ih is the most common on earth, and is obtained cooling the water below $0^{\circ} \mathrm{C}$ at ambient pressure; most of the works are focused in this type of ice since others only appear under very high pressures. From the articles previously indicated, it is possible to describe the mechanical properties of the ice. The elastic modulus of the ice increases when the temperature decreases; its value is in the range of 9-11 GPa [2]. Compressive strength is very sensitive to the strain rate and temperature; its value varies from 2 to $30 \mathrm{MPa}$ [7-11]. Finally the tensile strength is considered to be independent of strain rate and temperature with a value close to $2 \mathrm{MPa}[12,13]$.

Since the ice impact is a threat for the aeronautical industry it is necessary to increase the knowledge of this type of events. Impacts on composite laminate are very dangerous, since could cause internal delaminations which could rapidly grow if the structure is subjected to inplane shear 


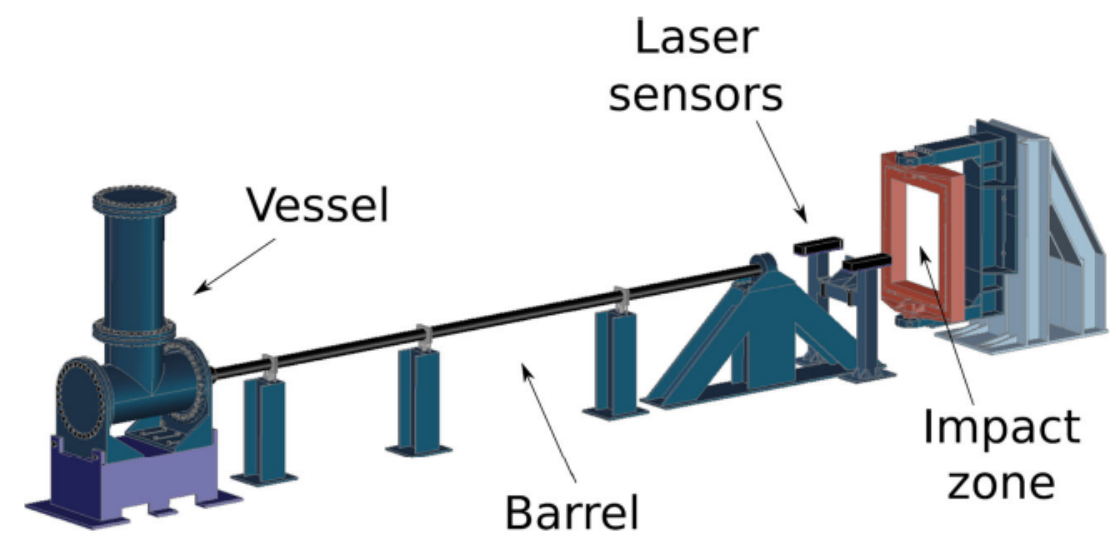

or compression [14-16]. The increase in use of composite laminates for many structural components in aircraft makes necessary to understand the force induced by the ice impact.

Different authors have investigated the effect of the ice impact. Some of them focused on the impact on plates of different materials (mainly composite laminates); Kim et al. [4, 17-19] published several works in which the high velocity impact of ice on composite laminates was investigated. In one of these works [19] the force induced by the ice during the impact in a reduced range of impact energies is analysed. More recently Carney et al. [20] performed high velocity impacts of ice cylinders on load cell in order to generate experimental data to validate an ice material model; the contact force was not quantified although it is distinguished from the load cell measurement. ApplebyThomas et al. [22] studied the effect of multiple impacts on carbon/epoxy composite panels; Combescure et al. [23] analysed the high velocity impact of cylindrical ice on both rigid and flexible targets. Hong et al. [24] focused its investigation in the impact of very small particles of ice on carbon/epoxy composite laminates. Finally it is important to mention the work of Tippmann et al. [21] in which a Hopkinson bar type setup (ballistic pendulum) has been used to measure the contact force during the impact; in addition an analysis of the crack growth is performed. All these works show the growing interest in this kind of studies.

Fig. 2 Images of a $30 \mathrm{~mm}$ diameter sabot
It is important to highlight that some of the aforementioned works uses the force measured by the load cell, as if it was the contact force between the ice and the plate where it impacts. Since the load cell could not be supported in an infinitely rigid structure, the values given by the load cell are not the same as the contact force ones. The objective of this work is to quantify the contact force during the high velocity impact of ice spheres on a rigid plate; this quantification is accomplished by means of the data obtained from the load cell and using a inverse analytical model. These results have not been obtained for any other author for this kind of impacts.

Three different spheres diameters (and hence masses) were considered in order to analyse its influence on both the force history and the maximum peak load; in particular an analysis of the influence of the impactor kinetic energy will be performed. In addition an analysis of the fragmentation process is carried out, using the high speed images obtained during the impact process. Since the measurement of the ice contact force has not been performed explicitly by any other author, the values obtained could be of great interest as benchmarks for the investigators which are developing constitutive models for the behaviour of the ice at high strain rates; also, structural aircraft engineers, could use the data provided in this work for design purposes.

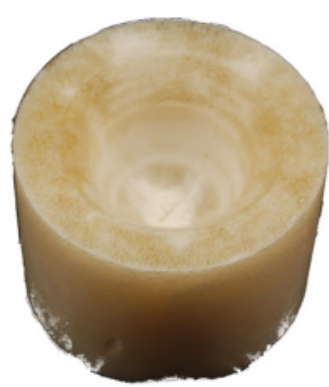

(b)

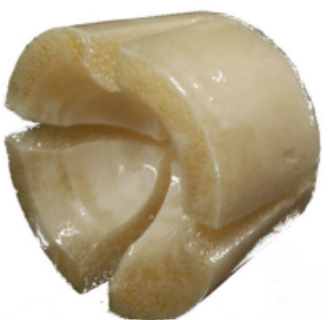

(c) 


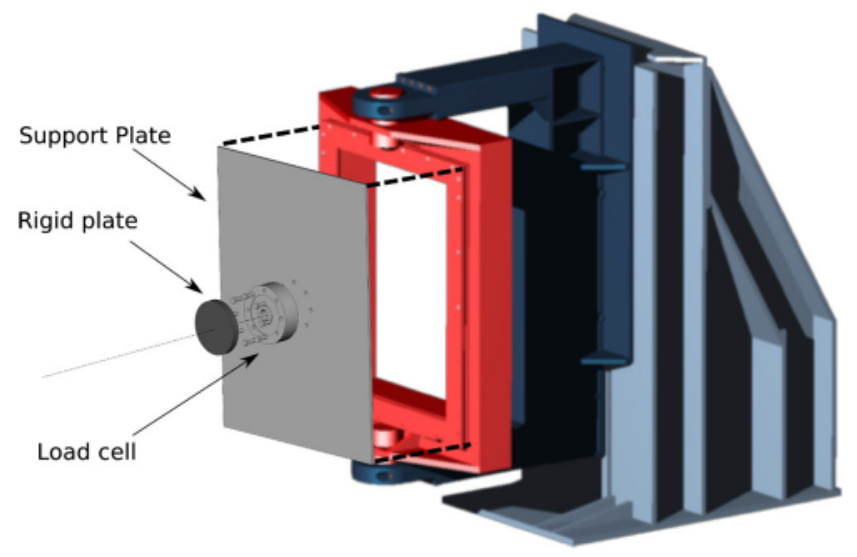

Fig. 3 Steel plate, load cell and impact structure used in experimental tests

\section{Experimental Tests}

\section{Experimental Set-Up}

In order to investigate how ice behaves under impact conditions, ice spheres were launched against a load cell measuring the force induced during the impact. The ice spheres were accelerated using a one stage light gas gun, which uses pressurized air to impel the projectile through a 5 meters long, $60 \mathrm{~mm}$ calibre barrel (Fig. 1). The impact velocity was measured by means of a laser sensor placed between the barrel muzzle and the target. In order to launch the ice sphere a sabot has been developed and manufactured. This sabot has two purposes, the first one to impel the projectiles of different diameters through the $60 \mathrm{~mm}$ barrel and the second one to isolate the ice from the friction during the acceleration, avoiding melting. To this end, the sabot was manufactured from polyurethane foam, and designed with aerodynamic shape and longitudinal cuts in order to allow the sabot separation from the projectile during the flight before the impact (Fig. 2). The ice sphere impacts on a cylindrical steel plate (Fig. 3) which is screwed to the load cell in order to measure the induced impact force. The load cell, model PB-2 manufactured by Microtest, was designed to measure load under

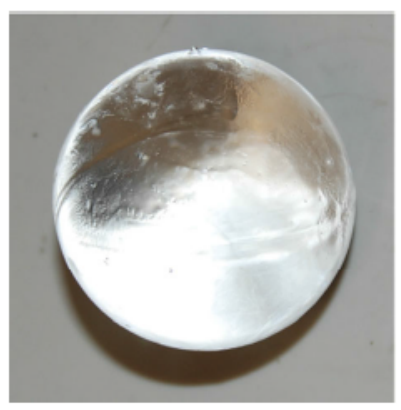

Fig. 4 Ice sphere projectile of $30 \mathrm{~mm}$ diameter impact conditions (it has a resonance frequency of 13230 $\mathrm{Hz}$ ). The data acquisition system employed to register the data measured by the load cell was a DEWETRON system specifically designed for dynamic applications, capable to capture data up to $1 \mathrm{MHz}$. The load cell has internally a full Wheatstone bridge, which is directly registered by the equipment without using a signal conditioner, avoiding any lag or undesirable electronic filter; the sampling frequency used was $500 \mathrm{kHz}$. Finally, the steel plate-load cell group was held to a backup structure as is shown in Fig. 3.

A Photron Ultima APX digital high-speed camera was used to record the impact, and to verify that the ice reaches the load cell without loosing its integrity. The selected frame rate $(18,000 \mathrm{fps})$, resolution $(512 \times 288$ pixels $)$ and shutter time $(4 \mu s)$ were chosen based on early testing, and represent an optimal trade off between available lighting and the minimization of blur in the images. The camera was placed to allow the perfect capture of the impact.

In order to analyse the effect of the projectile mass, impact velocity and kinetic energy on the induced impact force, three different ice sphere diameters (30, 40 and $50 \mathrm{~mm}$ ) were used; the impact velocity was varied from 50 to $250 \mathrm{~m} / \mathrm{s}$. All impact tests were conducted in the University Carlos III of Madrid impact laboratory.

\section{Sample Preparation}

Obtaining ice spheres by traditional freezing without cracks is not possible, the different densities between solid and liquid phases causes pre-stresses during the freeze process, cracking the ice. Because of this, ice sphere projectiles were manufactured in two steps: first a main ice block is frozen in an open container to avoid residual stresses, then it is melted into the desired sphere shape (Fig. 4).

The freezing process of the main block must be preferred directional, in order to obtain full density ice (without air bubbles). The difference between air dissolution of solid and liquid phase of water causes the growth of these air bubbles. Freezing directionally the ice allows to group these bubbles, allowing its removal. The micro structure obtained is columnar granular, which is different from the one formed in nature, but results showed by Kim et al. [19] and Combescure et al. [23] concluded that the effect of micro structure of ice can be neglected under impact conditions (at high strain rates). Once the main block is obtained without air bubbles, it is melted into the desired sphere shape; for this purpose two pre-warmed aluminium blocks (Fig. 5(a)), with semi spheres drilled in each part, melts the main block by a combination of low pressure (gravity load) and heat conduction (Fig. 5(b)). This technique was based in the pressure-melt mechanism discussed in different works $[13,25,26]$. It was observed that after the melt-moulding process the ice spheres were glossy, which 
Fig. 5 Aluminum mold and

scheme of the ice

melt-moulding process

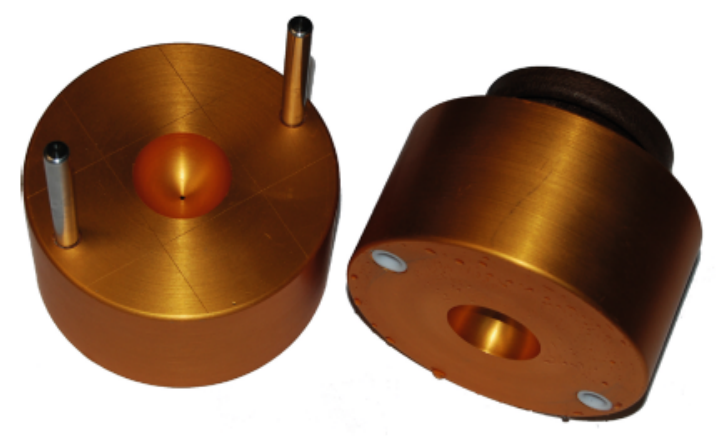

(a) Two pieces aluminum mold

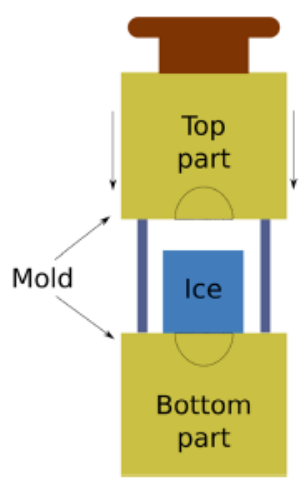

(b) Manufacturing

process

can be avoided conserving the ice sphere projectiles at $-10^{\circ} C$ during almost 2 hours before the impact. Using this technique, projectiles of 30,40 and $50 \mathrm{~mm}$ diameter were manufactured.

Since the ice properties are strongly dependent on the temperature $[6,27]$, the sabots were also conserved at the fridge until the impact test, allowing to maintain the ice temperature at $-10^{\circ} \mathrm{C}$ during the test. Impact tests were conducted under room conditions due to the fact that the impact results are independent of the room temperature as is shown by Pan and Render [28].

\section{Contact Force Induced by Ice Impact}

The engineers that design structures that could be subjected to any kind of impact and in particular ice impact, need to know the magnitude of the force that impact produces. The signal obtained from a load cell in a classical experimental test in which the load cell is impacted to measure the force induced by the impact, does not provide the real contact force between the projectile (in our case ice) and the plate where it impacts. The differences between the contact force and the force measured by the load cell could be due to the following reasons:

- Every load cell acts as a spring and the force measured is proportional to the relative movement of its faces (front and back faces).

Table 1 Modal frequencies determined by modal survey of the impact structure

\begin{tabular}{ll}
\hline$\omega_{1}$ & $295 \mathrm{~Hz}$ \\
$\omega_{2}$ & $4757 \mathrm{~Hz}$ \\
$\omega_{3}$ & $11506 \mathrm{~Hz}$ \\
\hline
\end{tabular}

- The load cell will measure oscillations due to the impact force and to the resonance of the load cell.

The first source of error could be minimized using a massive and highly stiff support for the load cell; this is because if the back side can move, the force measured is smaller than the contact force induced by the impact, leading to its undervaluation. In the second case, if the resonance frequency is much higher than the frequency of the impact force, its contribution could be removed by filtering; nevertheless filtering is sometimes a delicate issue if the frequency of the phenomenon observed is unknown. This could lead in a wrong measurement of the impact force (overestimate or underestimate).

In this work, in order to obtain the contact force between the ice projectile and the steel plate attached to the load cell, an inverse problem has been proposed to reconstruct the contact force from the signal obtained from the load cell. As will be explained later, the structure used to hold the load cell was not stiff enough and hence filtering was not a choice.

The inverse problem proposed in this work to obtain the real contact force between the ice projectile and the plate where it impacts, is based on a mass-spring system. This mass-spring system should reproduce the dynamic behaviour of the load cell and the whole structure used to support it. To define the topology of this system is necessary to know the modal frequencies; to this end a modal analyser OROS- 25 has been used. The OROS-25 studies, in the Fourier domain, the response of the structure under an excitation (in a range between $0-20 \mathrm{KHz}$ ). The structure has been hit using an instrumented hammer and its response to the excitation has been measured by an accelerometer. The excitation must be similar to the one generated by the ice impact. To achieve that, the hammer always hits the centre of the steel plate; the accelerometer measures the response at different positions in the structure. The modal analysis 
Fig. 6 Impact structure and mass-spring analogous system proposed

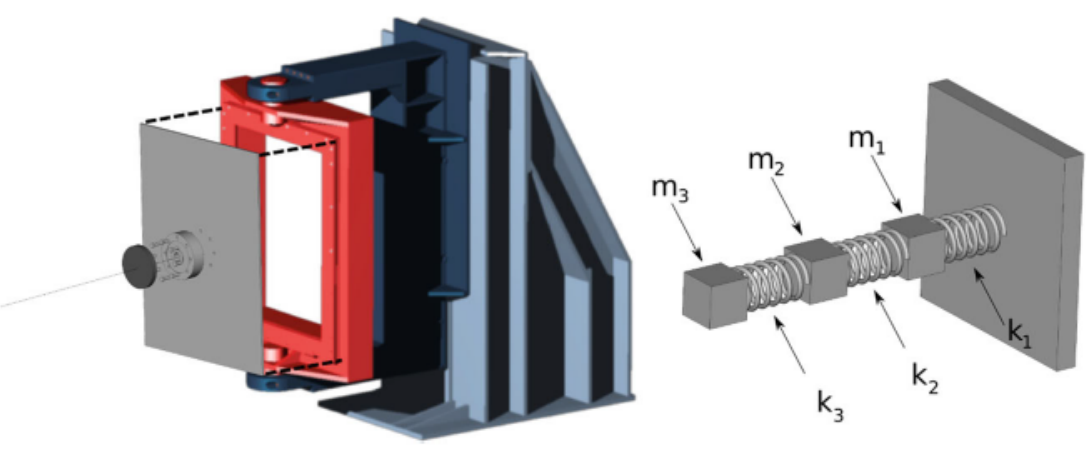

determines three main modal frequencies (see Table 1) and therefore indicates that a system of three degrees of freedom (composed by 3 masses and 3 springs) will reproduce the dynamic behaviour of the structure. The first mass and the first spring correspond to the backup support, the second mass and spring are related to the large support plate where the load cell is fixed, and finally the third spring corresponds to the load cell and the third mass to the rigid plate where the ice impacts (Fig. 6). A similar approach has been proposed by Carney et al. [20], but in that work the contact force was not calculated; the spring-mass model was included in a numerical simulation to validate an ice material model.

Some values of the masses and springs were provided by the load cell manufacturer ( $k_{3}$ and $m_{3}$ ), whereas $k_{2}$ was simply measured using a finite element simulation (the stiffness of a steel plate); the other three parameters were obtained using the modal frequencies. Finally the structure has been modelled with the values showed in Table 2 .

The dynamic response of the mass spring system can be easily represented by the equations:

$$
\begin{aligned}
& m_{1} \ddot{x}_{1}=k_{2}\left(x_{2}-x_{1}\right)-k_{1} x_{1} \\
& m_{2} \ddot{x}_{2}=-k_{2}\left(x_{2}-x_{1}\right)+k_{3}\left(x_{3}-x_{2}\right) \\
& m_{3} \ddot{x}_{3}=F_{3}-k_{3}\left(x_{3}-x_{2}\right)
\end{aligned}
$$

where $m_{i}$ and $k_{i}$ are respectively the masses and the springs of the system, $F_{3}$ is the contact force between the ice projectile and the steel plate during the impact, and $x_{i}, \ddot{x}_{i}$ are the displacements and accelerations of the different masses. Using this scheme it is easy to identify the force measured

Table 2 Mass and springs values of the inverse problem

\begin{tabular}{lll}
\hline Parameter & Value & Related to: \\
\hline$m_{1}$ & $17.8 \mathrm{~kg}$ & Back-up structure \\
$m_{2}$ & $5.1 \mathrm{~kg}$ & Large plate \\
$m_{3}$ & $5.545 \mathrm{~kg}$ & Plate where the ice impacts \\
$k_{1}$ & $1.61 \cdot 10^{10} \mathrm{~N} / \mathrm{m}$ & Back-up structure \\
$k_{2}$ & $3.096 \cdot 10^{7} \mathrm{~N} / \mathrm{m}$ & Large plate \\
$k_{3}$ & $1.3875 \cdot 10^{10} \mathrm{~N} / \mathrm{m}$ & Load cell \\
\hline
\end{tabular}

during the experimental test by the load cell and expressed by kinematic relations of the displacements of the masses:

$F_{c e l}=k_{3}\left(x_{3}-x_{2}\right)$

$F_{c e l}$ is the force registered by the load cell which is known. The system of equations (1) and (2), with the appropriate initial conditions $\left(x_{i}=0\right.$ and $\left.\dot{x}_{i}=0\right)$ gives a determined system. To this end a centred finite difference scheme is used for the second order derivative $\ddot{x}_{i}=$ $\left(x_{i}^{t+1}-2 x_{i}^{t}+x_{i}^{t-1}\right) / \Delta t^{2}$. The unknowns are the displacements at time $t+1\left(x_{1}^{t+1}, x_{2}^{t+1}\right.$ and $\left.x_{3}^{t+1}\right)$ and the contact force $\left(F_{3}^{t+1}\right)$. Since it is not possible to obtain an explicit solution for those four variables, an implicit one is used; hence for each time increment a matrix has to be inverted. Once it is solved, the contact force $F_{3}$ and the positions of all masses as function of time can be obtained allowing detailed studies of the dynamics of the impact.

\section{Results}

Once the experimental tests were accomplished, the results obtained have been employed in order to analyse the ice impact process. In this section, the force measured by the load cell in the experiments and the contact force induced by the ice impacts calculated by means of the mass-spring system, already mentioned, are presented.

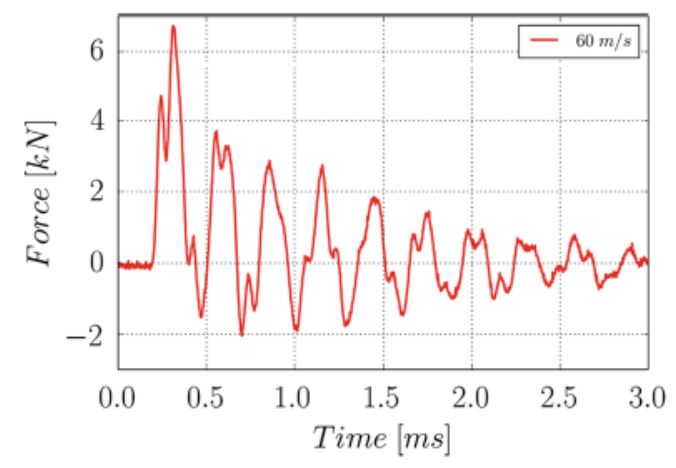

Fig. 7 Force measured by the load cell in an impact of $40 \mathrm{~mm}$ ice sphere diameter at $60 \mathrm{~m} / \mathrm{s}$ 


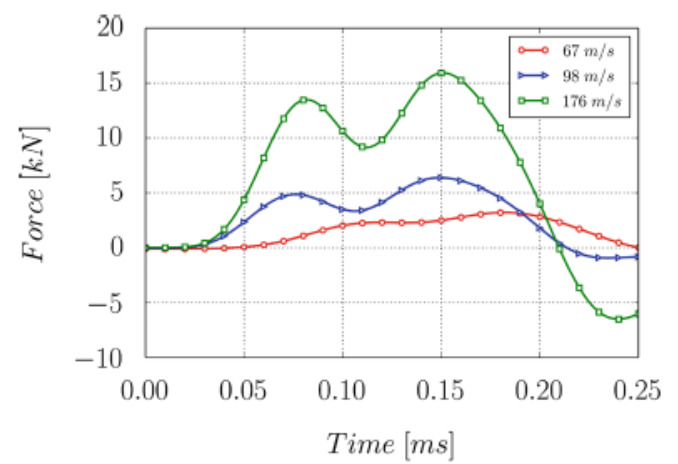

(a) $\phi 30 \mathrm{~mm}$

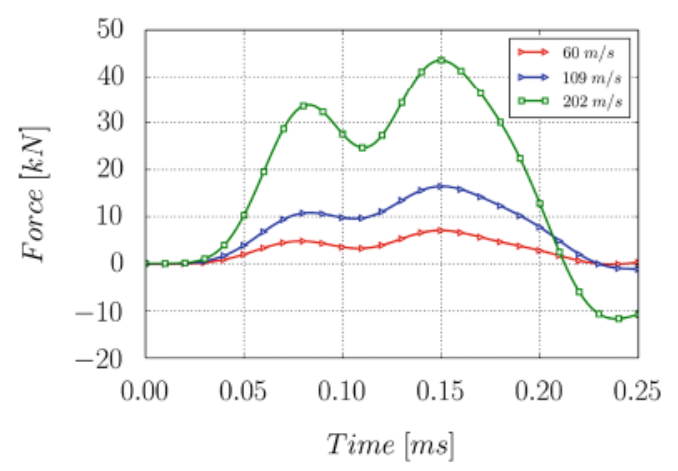

(b) $\phi 40 \mathrm{~mm}$

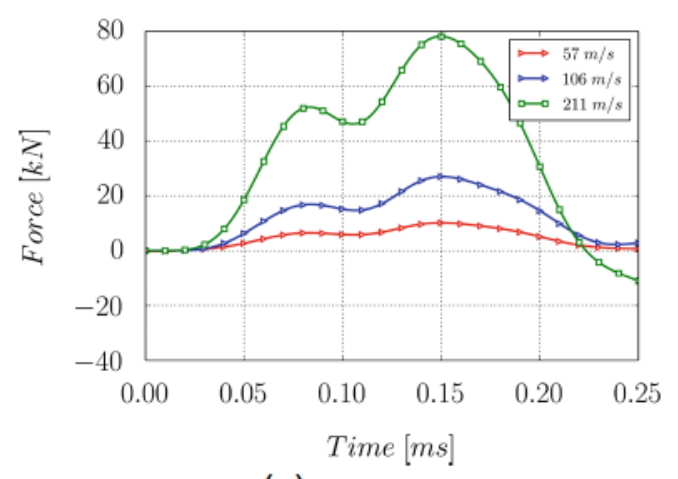

(C) $\phi 50 \mathrm{~mm}$

Fig. 8 Experimental force history for the three sphere diameter projectiles at different velocities

Figure 7 shows the force history measured by the load cell for an impact of a $40 \mathrm{~mm}$ diameter ice projectile at $60 \mathrm{~m} / \mathrm{s}$ (filtered using a $25 \mathrm{kHz}$ low-pass [20]). The maximum peak force is reached at the beginning of the impact and then the force follows a damping sinusoidal history; however this work is focused in the thread of ice impact which means to study the peak load and for this reason the damping was neglected. In order to analyse the peak force, Fig. 8 represent the first instants of the impact for the three ice projectile diameter considered at different velocities. All the force histories present a similar evolution in three stages: the first one corresponds to a sudden increase of the force reaching a relative maximum, followed by a slightly decrease or plateau; and at the last stage the force increases until reaching the maximum peak. The value of this peak increases with the projectile diameter and the impact velocity. The shape of the signal obtained from the load cell in all the tests suggests that it is strongly dominated by some vibration process and hence indicates that it is not the real contact force induced by the ice, since it is not possible from a physical point of view, that an ice impact may produce a curve with two different relative maximums. The force signal expected in a high velocity impact of an ice sphere is a smooth signal, with only one relative maximum because the projectile is spherical and hence at the beginning, the contact area is small and it increases smoothly. In the work of Kim et al. [19], the same type of curves (with two peaks) are obtained from the load cell, but in that case the authors do not calculate the ice contact force solving an inverse problem as it is proposed in the present work.

Solving the system of differential equations (1) by finite differences, as aforementioned, it is possible to obtain the contact force induced by the sphere impact on the steel plate. Figure 9 compares the contact force obtained by finite differences and the force measured by the load cell for an impact of a $40 \mathrm{~mm}$ ice projectile diameter at $109 \mathrm{~m} / \mathrm{s}$. In this case the contact force rises monotonously until a maximum peak and then drops suddenly to zero; the maximum peak value of the contact force is bigger than the one measured by the load cell. This result is expected since the load cell is fixed to a plate which can not be considered infinitely rigid, and hence the peak force registered is lower. Moreover there are differences between the trend of increase in both forces, the force measured by the load cell begin to increase later than the contact force calculated; this is because the ice force is applied in the steel plate and the load cell is behind the plate. Figure 10 shows the contact force for different projectile diameter and different impact velocities. As happened with the force measured by the load cell, all contact force histories present the same trend and the peak force increases as the ice diameter and velocity raise. The duration of the pulse for a given impact velocity, rises as the ice diameter increases as expected (this observation could be

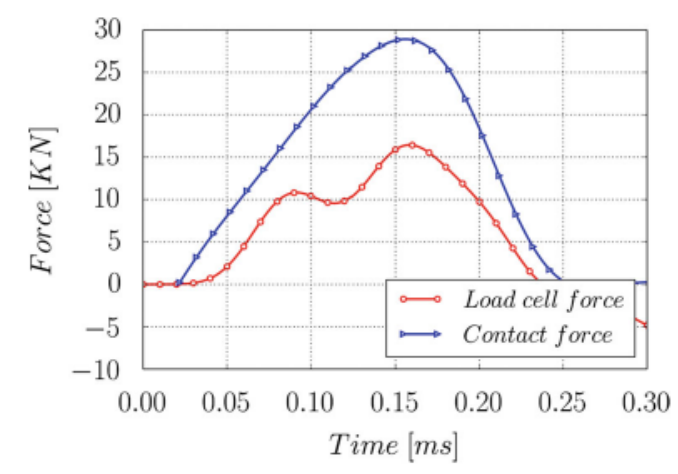

Fig. 9 Contact force and force in load cell by an impact of $40 \mathrm{~mm}$ ice sphere diameter at $109 \mathrm{~m} / \mathrm{s}$ 


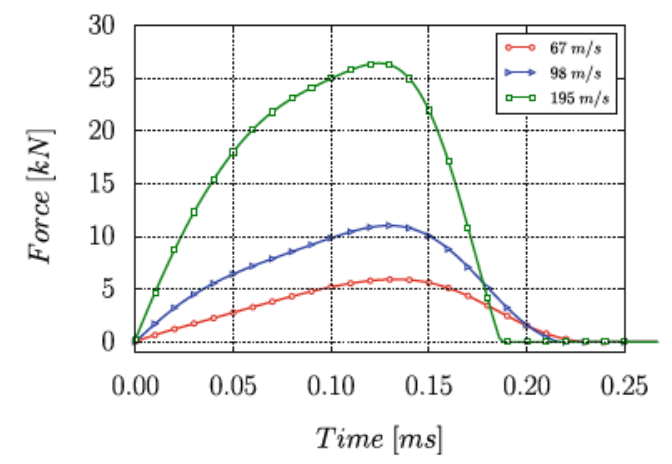

(a) $\phi 30 \mathrm{~mm}$

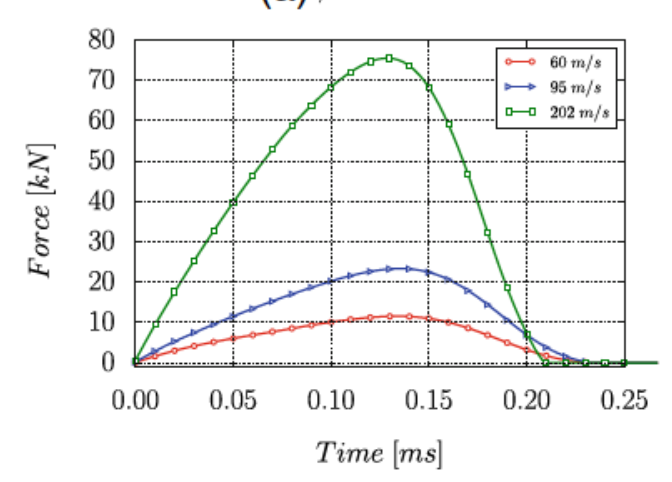

(b) $\phi 40 \mathrm{~mm}$

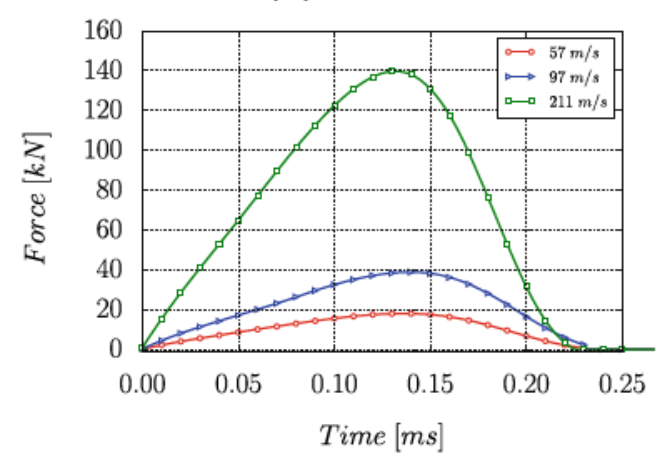

(C) $\phi 50 \mathrm{~mm}$

Fig. 10 Contact force history numerically obtained for the three sphere diameter projectiles at different velocities

identify for high velocity impacts cases); this effect was also observed in the work of Kim and Kedward [18]. Regarding the variation of the impact velocity for a given ice diameter, the duration of the pulse diminishes slightly as the impact velocity increases; this behaviour is expected since the duration of the impact should be proportional to the impact velocity.

Prior to analyse the results, is interesting to show that the experimental data exhibit scarce dispersion. Figure 11 shows the peak forces measured by the load cell as a function of impact velocity for the three different ice diameters. It can be observed how the peak force increases as the impact velocity does, following a linear path in which the scatter in the peak force results can be considered negligible.

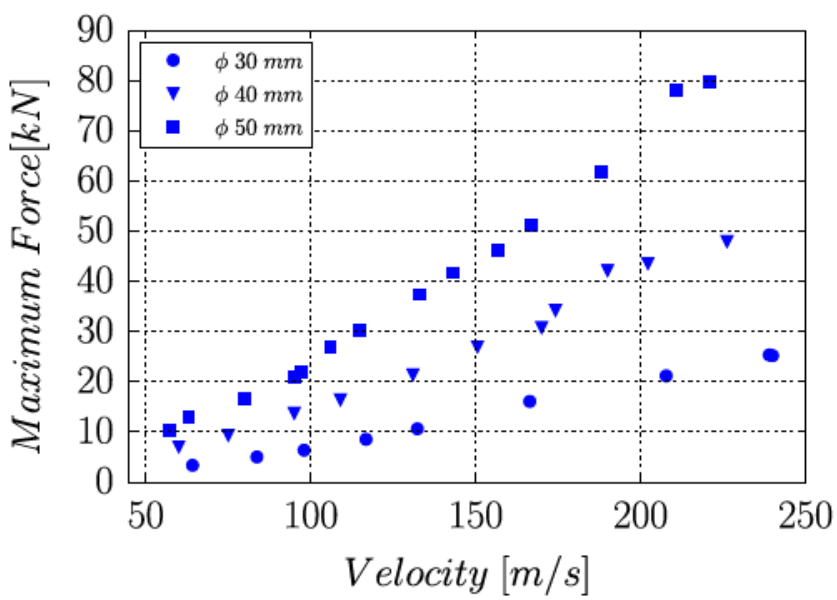

Fig. 11 Maximum measured force by the load cell against impact velocity for the three projectile diameters analyzed

\section{Analysis of the Experimental Tests}

In order to study dependences of the maximum peak forces, Fig. 12 shows the maximum impact force measured by the load cell and the maximum value of the contact force (obtained using the aforementioned model) versus the kinetic energy of the projectile for impacts of ice spheres of 30,40 and $50 \mathrm{~mm}$ diameter. It can be observed a dependence of the maximum peak force with the kinetic energy of the projectile independently of the spheres diameter. For instance two ice spheres of 30 and $50 \mathrm{~mm}$ of diameter produces the same maximum peak force if its kinetic energy is the same. The relation between maximum peak force and kinetic energy tends to a potential law as observed by Tippmann et al. [21]; in the current work this relation has been observed for higher values of impact energy (up to $1400 \mathrm{~J}$ instead of $400 \mathrm{~J}$ as in the work of Tipmann et al. [21]). Furthermore, the results show that the ratio between the peak forces (load cell force and contact force) remains

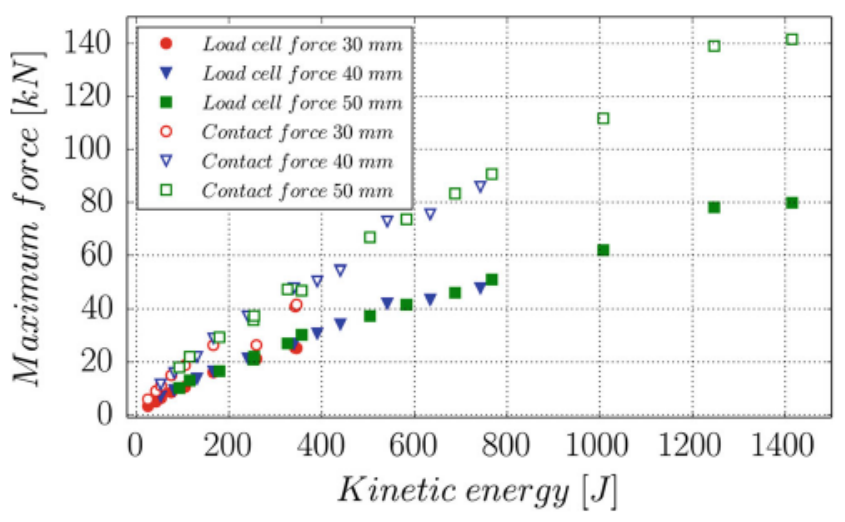

Fig. 12 Maximum measured force by the load cell and maximum contact force against kinetic energy of the projectile 


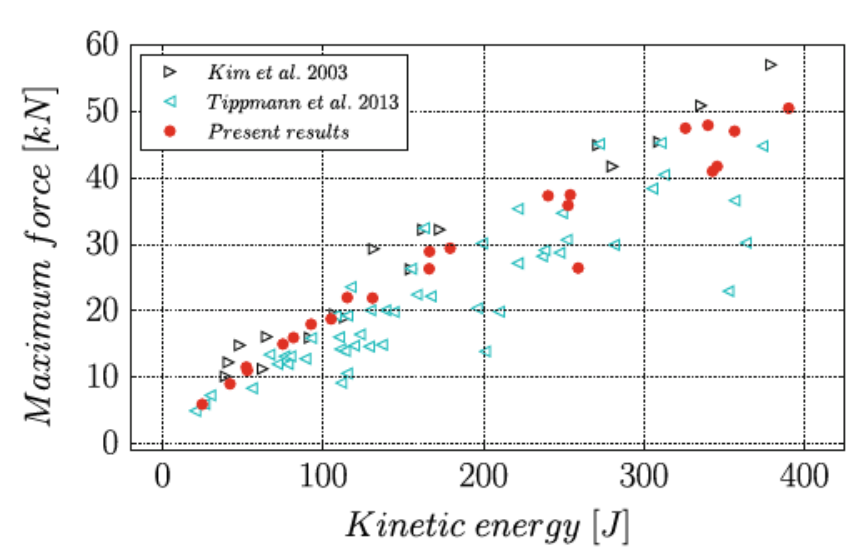

Fig. 13 Maximum contact force against kinetic energy of the projectile from different authors

constant as the kinetic energy of the projectile raises, so that the peak values of the contact force are around $75 \%$ bigger than the measured by the load cell in any case; this result is related to the experimental set-up used in the current work. If a more rigid back-up structure is used, the percentage will be lower, but the load cell will always underestimate the contact force. In addition if the resonance frequency of the load cell is removed (by filtering for instance) the difference will be smaller. This result is important since indicates that the force measured by instrumentation systems could be lower than the contact force and hence the results obtained could not be in the security side.
Once the contact force was numerically obtained it is possible to compare the results with other authors (Fig. 13). The results obtained in the current work and the values obtained by other authors are similar; although the experimental set-up in each investigation was different. Kim et al. [19] use a load cell, similar to the one used in the current tests, mounted between a titanium platen and a $50.8 \mathrm{~mm}$ thick steel plate. Due to the fact that its mounting support presents high stiffness, the difference between the contact force and the load cell measurement is small. On the other hand, Tippmann et al. [21] in 2013 measured the peak force using a Hopkinson bar type set-up (ballistic pendulum); as can be expected (because of the different experimental device to measure the force) the results differ from the obtained in this work, but the same trend and magnitude was observed.

The aforementioned dependence on the projectile kinetic energy could be explained attending to the ratio between the distortion energy density and the kinetic energy density. The first one $\left(U_{d i s t}\right)$ is related to the energy needed to deform the material up to failure, and in this case depends on the mechanical properties of the ice (which are very low). The second one $\left(U_{k}\right)$ is the kinetic energy of the ice projectile per unit of mass. This ratio is very small $U_{\text {dist }} / U_{k}=10^{-3}$ which means that the distortion energy density is negligible when compared to the kinetic energy density, and hence the impact is dominated by inertial effects. The details of this comparison could be found in a previous work of the authors

Fig. 14 Impact sequence frames for an impact of $30 \mathrm{~mm}$ ice projectile diameter at $98 \mathrm{~m} / \mathrm{s}$, recorded at $105000 \mathrm{fps}$

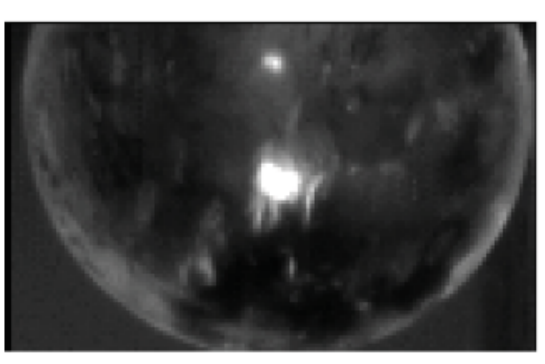

(a) $t=0 \mu \mathrm{s}$

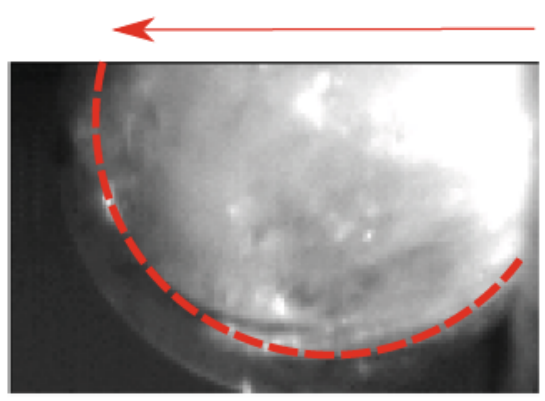

(c) $t=19.04 \mu \mathrm{s}$

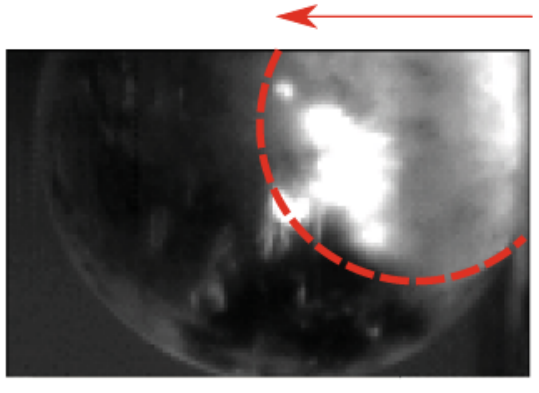

(b) $t=9.52 \mu \mathrm{s}$

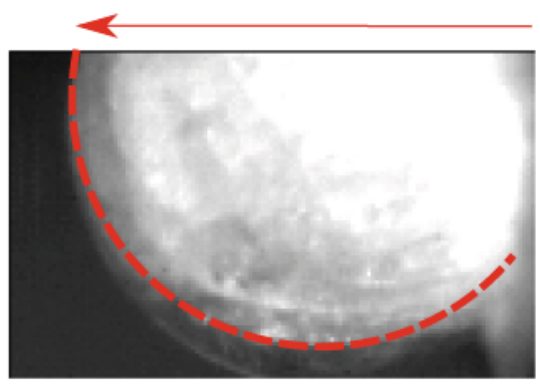

(d) $t=28.56 \mu \mathrm{s}$ 
Fig. 15 Impact sequence frames and force histories synchronized for an impact of $40 \mathrm{~mm}$ ice projectile diameter at $109 \mathrm{~m} / \mathrm{s}$
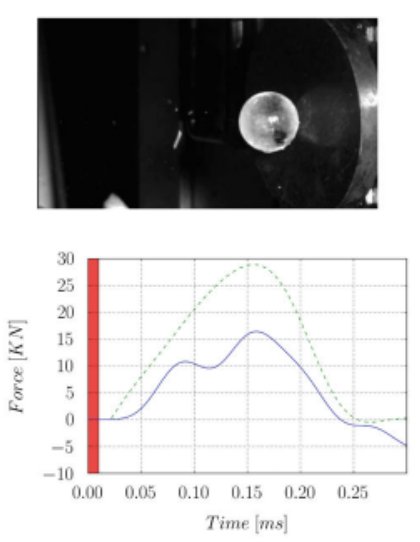

(a) $t=0 \mu s$
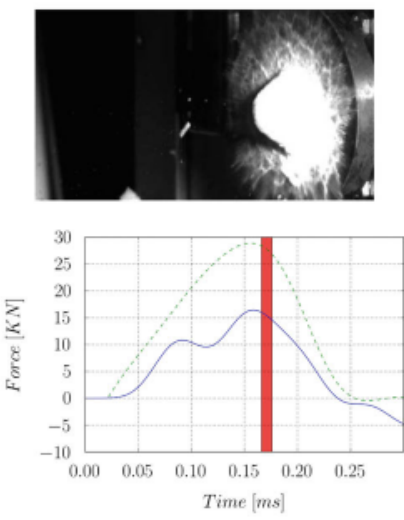

(d) $t=166 \mu \mathrm{s}$
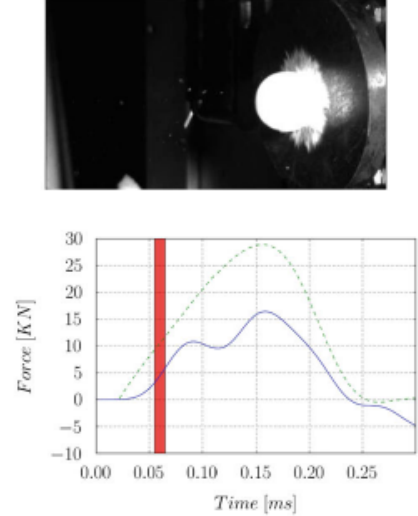

(b) $t=55 \mu \mathrm{s}$
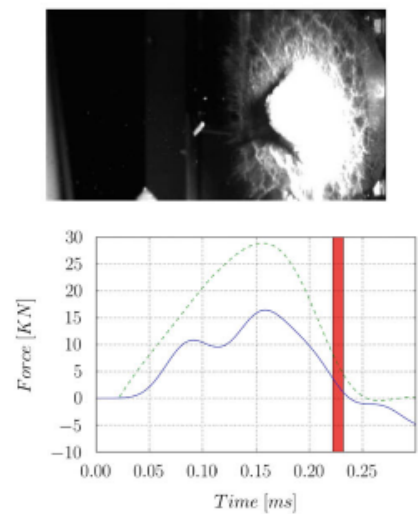

(e) $t=222 \mu \mathrm{s}$
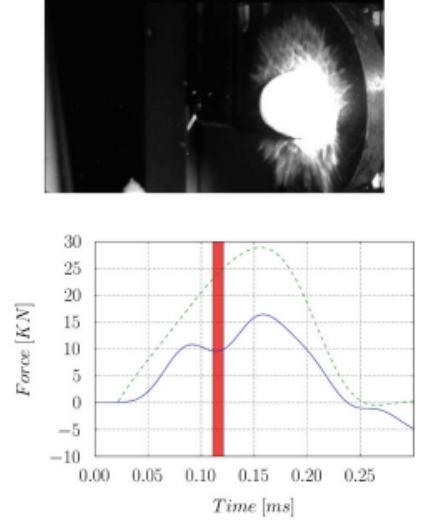

(c) $t=111 \mu \mathrm{s}$
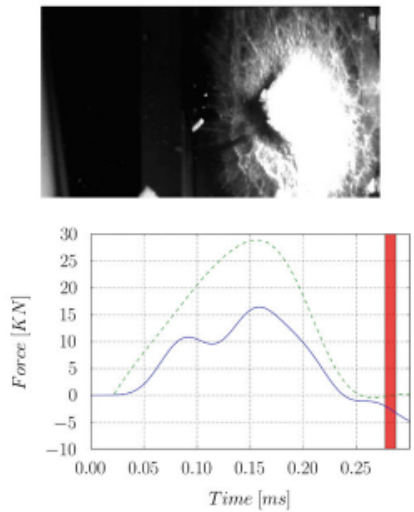

(f) $t=277 \mu \mathrm{s}$

[10]. A similar conclusion and value was obtained by Combescure et al. [23]; in that work the authors estimated that around $0.04 \mathrm{~J}$ are consumed by fracture energy for an impact of $60 \mathrm{~J}$, which is a ratio of approximately $10^{-3}$, the same order of magnitude stated in the current work.

In order to identify how and when the ice fails, in addition to the normal frame rate of $18000 \mathrm{fps}$, different videos were recorded increasing the frame rate. Figure 14 shows a sequence recorded at $105000 \mathrm{fps}$ for an impact of $30 \mathrm{~mm}$ projectile diameter at $98 \mathrm{~m} / \mathrm{s}$; at this frame rate the image size must be diminished, and hence only a part of the ice projectile is visualized. The dashed line indicates the fragmentation front position. Using these images it is possible to measure the fragmentation front velocity through the ice. Before impact the ice has transparency, but after it gets opaque due to the internal fragmentation. This effect is due to the new surfaces generated by the fragmentation propagation that reflect the incidence light, as it is observed in Fig. 14 [19]. It is known the strong dependency of the ice behaviour with the strain rate; the ductility of the ice at low strain rates becomes brittle behaviour as the strain rate increases [3, 29, 30]. At impact conditions the ice behaviour is brittle, and hence brittle cracks appear [6, 31, 32], causing the whitening opacity on ice spheres. This

change in the ice transparency will help in the determination of the fragmentation propagation [30, 32]. Since the fragmentation front starts in the impact point and propagates spherically, assuming a constant velocity it is possible to estimate the fragmentation front velocity $\left(V_{f}\right)$ at first approach as follows:

$V_{f} \sim \frac{\text { Projectile diameter }}{\text { time to full crack }}$

the ice projectile diameter is known for each impact test, and the time to full fragmentation is obtained using the velocity of frame recording ( $f p s$ ) set up in the high-speed camera. Using this technique an approximated value of $1050 \mathrm{~m} / \mathrm{s}$ could be estimated for the fragmentation front velocity inside the ice. A similar value was found by Combescure et al. [23]. This value of fragmentation velocity propagation could be compared with the maximum theoretical value proposed by different authors [33, 34], which is the wave speed in a free surface or Rayleigh velocity:

$V_{R} \sim c_{\perp}(0.874+0.162 v)=1842 \mathrm{~m} / \mathrm{s}$

where $c_{\perp}=\sqrt{E /(2 \rho(1+v)}$ is the speed propagation of transverse waves inside the ice, $E$ is the elastic modulus, $\rho$ the density and $v$ the Poisson ratio [10]. This theoretical 
value is proposed for a perfect homogeneous material, the ice spheres used in these experimental tests could present some imperfections that can be the reason for a lower value of fragmentation propagation. From these results could be concluded that when the impact velocity is significantly lower than the fragmentation front speed, the ice gets almost completely fragmented in the first instants of the impact due to the low distortion energy density that the ice presents. It is possible to state that during almost all the impact process, the ice projectile acts like an agglomeration of many tiny ice particles rather than a single solid, so that the main contribution to the induced impact force should be the kinetic energy, as can be observed in the experimental values showed in this paper.

Once it has been noted that the ice gets fragmented at the beginning of the impact, it is possible to analyse the trend of the contact force history. To this end, the test impacts were recorded using a high speed camera and the video was synchronized with the forces histories obtained, both load cell and the contact force (obtained with the aforementioned model). Therefore the images could be used to analyse the evolution of the forces during the impact. The sequence of video-frames and graphs (Fig. 15) represents the impact at different times and the forces at each time for an impact of $40 \mathrm{~mm}$ sphere ice diameter at $109 \mathrm{~m} / \mathrm{s}$, shadowing in the graph the corresponding time of each frame. It is important to note that the maximum of the contact force is reached at $t=150 \mu s$ (close to the frame (d)), and as it can be seen, at that moment less than half of the ice sphere has contacted the steel plate. After the maximum, the force history decreases drastically due to the fact that the ice is not able to transfer more momentum in the direction of the impact; in fact, it is possible to observe in the images that the trajectory of the ice after this point is parallel to the plate and radial. This is possible since, as stated before, the ice acts as an agglomeration of many particles that are easy to deviate.

\section{Conclusions}

In this work the analysis of the force induced by the high velocity impact of ice spheres has been accomplished. High velocity impact tests have been performed in a wide range of impact energies and for three different ice spheres diameters. An experimental procedure has been developed in order to launch ice spheres at high velocities and to measure the impact force using a load cell. To this end a special sabot has been developed which isolate the ice during the acceleration and protects it. In order to obtain the contact force between the ice and the plate, an inverse problem based on a spring-mass model has been developed. From these results presented and discussed, the main conclusions are as follows:
- The inverse problem proposed has proven to be helpful to obtain the contact force in high velocity impact tests, when the support structure is not massive and stiff enough and when the frequency promoted by the impact is undetermined (then no filtering is possible).

- The impact force registered by the load cell has two relative maximums, which appear because of the flexibility of the backup structure. The contact force, between the ice and the plate where it impacts, calculated by means of the spring-mass model proposed has only one maximum which is the expected result.

- The maximum peak force (for both the force registered by the load cell and the contact force) appears to be function of the impact energy, despite the ice diameter. This effect appear because the distortion energy density is negligible compared to the ice projectile kinetic energy.

- When calculating the contact force produced by the ice impact, it appears to be $75 \%$ higher than the value obtained from the load cell; this difference appears because of the low stiffness of the backup structure. This means that the force measured experimentally could have sensible errors and in addition those could be in the non-security side.

- The analysis of the fragmentation process of the ice during the impact, shows that the ice is fragmented at very early stage of the impact and hence it behaves as an agglomeration of particles rather than a solid structure. This result supports that the ice size does not influence the impact force induced on the plate, only the impact energy.

Acknowledgments This research was done with the financial support of the Spanish Ministry of Economy and Competitiveness under Project reference DPI2013-41094-R.

\section{References}

1. Varas D, Lopez-Puente J, Zaera R (2012) Numerical analysis of the hydrodynamic ram phenomenon in aircraft fuel tanks. AIAA J 50(7):1621-1630

2. Cole DM (2001) The microstructure of ice and its influence on mechanical properties. Eng Frac Mech 68(17-18):1797-1822

3. Dutta PK, Cole DM, Schulson EM, Sodhi DS (2003) A Fracture Study of Ice Under High Strain Rate Loading Quasi-Static Tests E-Curve. Int Offshore Polar Eng Conf 5:465-472

4. Kim H, Keune JN (2007) Compressive strength of ice at impact strain rates. J Mater Sci 42(8):2802-2806

5. Shazly M, Prakash V, Lerch BA (2009) High strain-rate behavior of ice under uniaxial compression. Int J Solids Struct 46(6):1499_ 1515

6. Schulson E (2001) Brittle failure of ice. Eng Frac Mech 68(1718):1839-1887

7. Dutta PK (1993) Compressive failure of polycrystalline ice under impact. Int Offshore Polar Eng Conf:573-580 
8. Jones SJ (1997) High Strain-Rate Compression Tests on Ice. J Phys Chem B 101(32):6099-6101

9. Fasanella EL, Boitnott RL (2006) Dynamic Crush Characterization of Ice, Tech. Rep/ NASA

10. Pernas-Sánchez J, Pedroche D, Varas D, López-Puente J, Zaera R (2012) Numerical modeling of ice behavior under high velocity impacts. Int J Solids Struct 49(14):1919-1927

11. Wu X, Prakash V (2015) Dynamic strength of distill water and lake water ice at high strain rates. Int J Impact Eng 76(0):155-165

12. Petrovic JJ (2003) Mechanical properties of ice and snow. J Mater Sci 38:1-6

13. Kermani M, Farzaneh M, Gagnon R (2008) Bending strength and effective modulus of atmospheric ice. Cold Reg Sci Technol 53(2):162-169

14. López-Puente J, Zaera R, Navarro C (2007) An analytical model for high velocity impacts on thin CFRPs woven laminated plates. Int J Solids Struct 44(9):2837-2851

15. López-Puente J, Zaera R, Navarro C (2008) Experimental and numerical analysis of normal and oblique ballistic impacts on thin carbon/epoxy woven laminates. Compos A: Appl Sci Manuf 39(2):374-387

16. Varas D, Artero-Guerrero J, Pernas-Sánchez J, López-Puente J (2013) Analysis of high velocity impacts of steel cylinders on thin carbon/epoxy woven laminates. Compos Struct 95:623-629

17. Kim H, Kedward KT (1999) AIAA-99-1366 Experimental and numerical analysis correlation of hail ice impacting composite structures. Compos Struct 68(1):1-11

18. Kim H, Kedward KT (2000) Modeling hail ice impacts and predicting impact damage initiation in composite structures. AIAA J 38(7):1278-1288

19. Kim H, Welch DA, Kedward KT (2003) Experimental investigation of high velocity ice impacts on woven carbon / epoxy composite panels. Compos A 34:25-41

20. Carney K, Benson D, Dubois P, Lee R (2006) A phenomenological high strain rate model with failure for ice. Int J Solids Struct 43(25-26):7820-7839

21. Tippmann JD, Kim H, Rhymer JD (2013) Experimentally validated strain rate dependent material model for spherical ice impact simulation. Int J Impact Eng 57:43-54
22. Appleby-Thomas GJ, Hazell PJ, Dahini G (2011) On the response of two commercially-important cfrp structures to multiple ice impacts. Compos Struct 93(10):2619-2627

23. Combescure A, Chuzel-Marmot Y, Fabis J (2011) Experimental study of high-velocity impact and fracture of ice. Int J Solids Struct 48(20):2779-2790

24. Hong YK, Park C, Baek SW (2009) High-velocity impact of ice particles on a composite material. J Compos Mater 43(17):1819_ 1834

25. Timco G, Frederking R (1995) Experimental investigations of the behavior of ice at the contact zone. Mech Geomaterial Interfaces 42:35-55

26. Li Y, Somorjai GA (2007) Surface premelting of ice. J Phys Chem C 111(27):9631-9637

27. Hooke RL, Mellor M (1980) Mechanical properties of polycrystalline knowledge and priorities for research in ice: an assesment of current report prepared for the international commission on snow and ice, with support from the U.S National scientific. Cold Reg Sci Technol Sci 3:263-275

28. Pan H, Render PM (1996) Impact Characteristics of Hailstones Simulating Ingestion by Turbofan Aeroengines. J Propuls Power 12(3): $457-462$

29. Rhymer J, Kim H, Roach D (2012) The damage resistance of quasi-isotropic carbon/epoxy composite tape laminates impacted by high velocity ice. Compos A: Appl Sci Manuf 43(7):1134 1144

30. Wachter LM, Renshaw CE, Schulson EM (2009) Transition in brittle failure mode in ice under low confinement. Acta Materialia 57(2):345-355

31. Ashby M, Hallam S (1986) The failure of brittle solids containing small cracks under compressive stress states. Acta Metallurgica 34(3):497-510

32. Weiss J, Schulson E (2009) Coulombic faulting from the grain scale to the geophysical scale: lessons from ice. J Phys D: Appl Phys 42(21):214017

33. Landau L, Lifshitz E (1986) Theory of the Elasticity. Pergamon Press, New York

34. Braun M, Fernández-Sáez J (2014) A new 2D discrete model applied to dynamic crack propagation in brittle materials. Int $\mathbf{J}$ Solids Struct 51(21-22):3787-3797 